\title{
Tendència universitària en la Borriana del segle XXI
}

\author{
Antoni Gil TriLles (agil@uji.es) \\ Departament de Matemàtiques. Universitat Jaume I
}

\section{Introducció}

Molts són els estudis estadístics que es generen any rere any sobre els resultats de les Proves d'Accés a la Universitat i la preinscripció i admissió universitària. Però els estudis solen ser molt generals i no permeten traure conclusions sobre l'estudiantat d'una determinada ciutat. Per la transcendència social del que representa estudiar a la universitat i per la meua especial vinculació, des de fa dinou cursos acadèmics, amb el món de l'admissió universitària, que em permetia obtindre dades més concretes, em vaig decidir a fer un estudi detallat de les preferències i realitats dels estudis universitaris dels joves borrianencs i borrianenques en els últims cinc anys.

\section{Els estudis de batxillerat a Borriana}

Tres són els centres educatius borrianencs que imparteixen estudis de primer i segon de batxillerat i són la porta directa per a accedir a la universitat. Dos d'ells són públics, l'IES Jaume I i l'IES Llombai, i un és concertat, el Col-legi Salesians. També hi ha algunes estudiantes i estudiants del nostre poble que cursen estudis de batxillerat en centres de localitats pròximes, com ara Almassora, Vila-real o Castelló, sobretot els que desitgen estudiar estudis de caràcter artístic, atès que aquesta modalitat de batxillerat no s'imparteix en cap dels tres centres de Borriana.

Dels poc menys de 35.000 habitants (34.683) que tenia la nostra ciutat segons el cens oficial del 2019, el percentatge de joves que es presenten a les Proves d'Accés a la Universitat (PAU) per a poder estudiar un grau universitari pot semblar baix, aproximadament el $0,45 \%$, és a dir, menys de cinc per cada mil habitants.

Aquesta és la informació detallada dels últims cinc anys en la convocatòria ordinària de les Proves d'Accés:

2015

\begin{tabular}{l|c|c|c|c|c|}
\hline \multicolumn{1}{|c|}{ CENTRE } & $\begin{array}{c}\text { PRESENTATS A } \\
\text { LES PAU }\end{array}$ & APTES & $\begin{array}{c}\text { MITJANA DE } \\
\text { L'EXPEDIENT DE } \\
\text { BATXILLERAT }\end{array}$ & $\begin{array}{c}\text { MITJANA } \\
\text { DE LA FASE } \\
\text { OBLIGATÒ } \\
\text { DE LES PAU }\end{array}$ & $\begin{array}{c}\text { DIFERÈNCIA } \\
\text { BATXILLERAT } \\
\text { I PAU }\end{array}$ \\
\hline IES Jaume I & 27 & 27 & 7,472 & 6,526 & 0,946 \\
\hline IES Llombai & 52 & 51 & 7,008 & 6,079 & 0,929 \\
\hline Col. Salesians & 54 & 54 & 7,833 & 6,956 & 0,877 \\
\hline
\end{tabular}


2016

\begin{tabular}{|l|c|c|c|c|c|}
\hline \multicolumn{1}{|c|}{ CENTRE } & $\begin{array}{c}\text { PRESENTATS A } \\
\text { LES PAU }\end{array}$ & APTES & $\begin{array}{c}\text { MITJANA DE } \\
\text { L'EXPEDIENT DE } \\
\text { BATXILLERAT }\end{array}$ & $\begin{array}{c}\text { MITJANA } \\
\text { DE LA FASE } \\
\text { OBLIGATÒRIA } \\
\text { DE LES PAU }\end{array}$ & $\begin{array}{c}\text { DIFERENCIA } \\
\text { BATXILLERAT } \\
\text { I PAU }\end{array}$ \\
\hline IES Jaume I & 17 & 17 & 7,769 & 6,743 & 1,026 \\
\hline IES Llombai & 46 & 46 & 7,350 & 6,321 & 1,029 \\
\hline Col. Salesians & 71 & 71 & 7,560 & 7,119 & 0,441 \\
\hline
\end{tabular}

$\begin{array}{lll}\text { Totals } & 134 & 134\end{array}$

2017

\begin{tabular}{|l|c|c|c|c|c|}
\hline \multicolumn{1}{|c|}{ CENTRE } & $\begin{array}{c}\text { PRESENTATS A } \\
\text { LES PAU }\end{array}$ & APTES & $\begin{array}{c}\text { MITJANA DE } \\
\text { L'EXPEDIENT DE } \\
\text { BATXILLERAT }\end{array}$ & $\begin{array}{c}\text { MITJANA } \\
\text { DEA FASE } \\
\text { OBLIGATORIA } \\
\text { DE LES PAU }\end{array}$ \\
\hline IES Jaume I & 20 & 20 & 7,868 & 7,055 \\
BIFATXILLERAT \\
I PAU
\end{tabular}

Totals

131

129

2018

\begin{tabular}{|l|c|c|c|c|c|}
\hline \multicolumn{1}{|c|}{ CENTRE } & $\begin{array}{c}\text { PRESENTATS A } \\
\text { LES PAU }\end{array}$ & APTES & $\begin{array}{c}\text { MITJANA DE } \\
\text { LEXPEDIENT DE } \\
\text { BATXILLERAT }\end{array}$ & $\begin{array}{c}\text { MITJANA } \\
\text { DE LA FASE } \\
\text { OBLIGATÒRIA } \\
\text { DE LES PAU }\end{array}$ & $\begin{array}{c}\text { DIFERÈNCIA } \\
\text { BATXILLERAT } \\
\text { I PAU }\end{array}$ \\
\hline IES Jaume I & 29 & 29 & 7,320 & 6,230 & 1,090 \\
\hline IES Llombai & 48 & 48 & 7,578 & 6,509 & 1,069 \\
\hline Col. Salesians & 61 & 60 & 7,297 & 6,502 & 0,795 \\
\hline
\end{tabular}

$\begin{array}{lll}\text { Totals } & 138 & 137\end{array}$

2019

\begin{tabular}{|l|c|c|c|c|c|}
\hline \multicolumn{1}{|c|}{ CENTRE } & $\begin{array}{c}\text { PRESENTATS A } \\
\text { LES PAU }\end{array}$ & APTES & $\begin{array}{c}\text { MITJANA DE } \\
\text { L'EXPEDIENT DE } \\
\text { BATXILLERAT }\end{array}$ & $\begin{array}{c}\text { MITJANA } \\
\text { DE LA FASE } \\
\text { OBLIGATÒRIA } \\
\text { DE LES PAU }\end{array}$ & $\begin{array}{c}\text { DIFERÈNCIA } \\
\text { BATXILLERAT } \\
\text { I PAU }\end{array}$ \\
\hline IES Jaume I & 33 & 32 & 7,310 & 6,377 & 0,933 \\
\hline IES Llombai & 59 & 54 & 7,551 & 6,114 & 1,437 \\
\hline Col. Salesians & 62 & 61 & 7,618 & 6,350 & 1,268 \\
\hline
\end{tabular}

Totals

154

147

En aquests últims cinc anys, de l'estudiantat dels tres centres, un total de 679 (el 98,41\% de l'alumnat presentat) han pogut demanar titulació universitària en condicions òptimes respecte al seu aprofitament en els estudis.

En la convocatòria extraordinària, en les PAU de juliol, els números, tot i que ja no són gens significatius, són els següents: 


\section{5}

\begin{tabular}{|l|c|c|c|c|c|}
\hline \multicolumn{1}{|c|}{ CENTRE } & $\begin{array}{c}\text { PRESENTATS A } \\
\text { LES PAU }\end{array}$ & APTES & $\begin{array}{c}\text { MITJANA DE } \\
\text { L'EXPEDIENT DE } \\
\text { BATXILLERAT }\end{array}$ & $\begin{array}{c}\text { MITJANA } \\
\text { DE LA FASE } \\
\text { OBLIGATÓRIA } \\
\text { DE LES PAU }\end{array}$ & $\begin{array}{c}\text { DIFERÈNCIA } \\
\text { BATXILLERAT } \\
\text { I PAU }\end{array}$ \\
\hline IES Jaume I & 7 & 7 & 6,097 & 5,290 & 0,807 \\
\hline IES Llombai & 17 & 15 & 6,003 & 5,692 & 0,311 \\
\hline Col. Salesians & 11 & 11 & 5,922 & 5,310 & 0,612 \\
\hline
\end{tabular}

Totals

35

33

\section{6}

\begin{tabular}{l|c|c|c|c|c|}
\hline \multicolumn{1}{|c|}{ CENTRE } & $\begin{array}{c}\text { PRESENTATS A } \\
\text { LES PAU }\end{array}$ & APTES & $\begin{array}{c}\text { MITJANA DE } \\
\text { L'EXPEDIENT DE } \\
\text { BATXILLERAT }\end{array}$ & $\begin{array}{c}\text { MITJANA } \\
\text { DE LA FASE } \\
\text { OBLIGATÒRIA } \\
\text { DE LES PAU }\end{array}$ & $\begin{array}{c}\text { DIFERÈNCIA } \\
\text { BATXILLERAT } \\
\text { I PAU }\end{array}$ \\
\hline IES Jaume I & 12 & 12 & 6,382 & 5,314 & 1,068 \\
\hline IES Llombai & 10 & 10 & 6,046 & 5,251 & 0,795 \\
\hline Col. Salesians & 8 & 8 & 5,953 & 4,827 & 1,126 \\
\hline
\end{tabular}

\section{7}

\begin{tabular}{|l|c|c|c|c|c|}
\hline \multicolumn{1}{|c|}{ CENTRE } & $\begin{array}{c}\text { PRESENTATS A } \\
\text { LES PAU }\end{array}$ & APTES & $\begin{array}{c}\text { MITJANA DE } \\
\text { L'EXPEDIENT DE } \\
\text { BATXILLERAT }\end{array}$ & $\begin{array}{c}\text { MITJANA } \\
\text { DE LA FASE } \\
\text { OBLIGATÒIA } \\
\text { DE LES PAU }\end{array}$ & $\begin{array}{c}\text { DIFERÈNCIA } \\
\text { BATXILLERAT } \\
\text { I PAU }\end{array}$ \\
\hline IES Jaume I & 10 & 7 & 6,411 & 4,370 & 2,041 \\
\hline IES Llombai & 8 & 7 & 6,624 & 5,031 & 1,593 \\
\hline Col. Salesians & 6 & 5 & 5,962 & 4,694 & 1,268 \\
\hline
\end{tabular}

Totals

24

19

\section{8}

\begin{tabular}{l|c|c|c|c|c|}
\hline \multicolumn{1}{|c|}{ CENTRE } & $\begin{array}{c}\text { PRESENTATS A } \\
\text { LES PAU }\end{array}$ & APTES & $\begin{array}{c}\text { MITJANA DE } \\
\text { LEXPEDIENT DE } \\
\text { BATXILLERAT }\end{array}$ & $\begin{array}{c}\text { MITJANA } \\
\text { DE LA FASE } \\
\text { OBLIGATÒRIA DE } \\
\text { LES PAU }\end{array}$ & $\begin{array}{c}\text { DIFERÈNCIA } \\
\text { BATXILLERAT } \\
\text { I PAU }\end{array}$ \\
\hline IES Jaume I & 13 & 9 & 6,348 & 4,422 & 1,926 \\
\hline IES Llombai & 5 & 5 & 6,486 & 5,632 & 0,854 \\
\hline Col. Salesians & 10 & 8 & 6,042 & 4,626 & 1,416 \\
\hline
\end{tabular}

\section{9}

\begin{tabular}{l|c|c|c|c|c|}
\hline \multicolumn{1}{|c|}{ CENTRE } & $\begin{array}{c}\text { PRESENTATS A } \\
\text { LES PAU }\end{array}$ & APTES & $\begin{array}{c}\text { MITJANA DE } \\
\text { L'EXPEDIENT DE } \\
\text { BATXILLERAT }\end{array}$ & $\begin{array}{c}\text { MITJANA } \\
\text { DE LA FASE } \\
\text { OBLIGATÒRIA DE } \\
\text { LES PAU }\end{array}$ & $\begin{array}{c}\text { DIFERÈNCIA } \\
\text { BATXILLERAT } \\
\text { I PAU }\end{array}$ \\
\hline IES Jaume I & 3 & 3 & 6,420 & 5,243 & 1,177 \\
\hline IES Llombai & 4 & 4 & 7,173 & 5,421 & 1,752 \\
\hline Col. Salesians & 4 & 1 & 5,725 & 3,712 & 2,013 \\
\hline
\end{tabular}




\section{Preferència universitària de la joventut borrianenca}

En el capítol anterior hem estudiat el nombre d'estudiantat que ha cursat estudis de batxillerat en els tres centres educatius borrianencs, però les dades que hi consten fan referència a aquelles $i$ aquells que han cursat estudis en els nostres centres, sense diferenciar si són o no nascuts ací, igual que també hi ha estudiantat nostre que ha estudiat en centres d'altres ciutats. En aquest apartat de la investigació, que consisteix en l'estudi de quins graus universitaris desitgen cursar, sí que ens centrarem únicament en estudiantat censat a Borriana.

L'estudi està fet a partir de les titulacions que han fet constar com a primera preferència en el moment de fer la preinscripció universitària en els últims cinc anys, des del 2015 fins al 2019. Aquesta última preinscripció és la que permetia estudiar en la universitat en l'actual curs 2019-2020.

La quantitat d'estudiantat borrianenc que ha fet les gestions pertinents per a poder cursar estudis universitaris ha sigut de 1.202; per anys: 276 en 2015, 243 en 2016, 242 en 2017, 220 en 2018, i 221 en 2019. El total és lleugerament més elevat en el primer curs perquè en aquest consten també les persones que han fet preinscripció en cursos anteriors i en 2015 en feien una segona o tercera petició. Les quantitats de cada curs són significativament majors que les dels que han estudiat en l'IES Jaume I, l'IES Llombai o el Col-legi Salesians i no corresponen exactament a la quantitat de peticions de preinscripció presentades (302 en 2015, 278 en 2016, 272 en 2016, 245 en 2018, i 249 en 2019) perquè ara s'hi inclouen els que, sent de Borriana, han estudiat batxillerat en qualsevol centre educatiu, i també els que fan preinscripció universitària però no han fet les PAU.

El centre de batxillerat de procedència de l'estudiantat que ha fet preinscripció en els últims cinc anys és el següent:

\begin{tabular}{|l|c|}
\hline CENTRE & QUANTITAT \\
\hline Col·legi Salesians & 442 \\
\hline IES Llombai & 327 \\
\hline IES Jaume I & 215 \\
\hline IES Matilde Salvador & 12 \\
\hline IES Miralcamp & 12 \\
\hline IES Broch i Llop & 11 \\
\hline Col·legi Santa María & 8 \\
\hline IES Gilabert de Centelles & 6 \\
\hline Col·legi Consolació & 6 \\
\hline Col·legi Miralvent & 5 \\
\hline IES Ribalta & 5 \\
\hline Lledó Intern. School & 5 \\
\hline
\end{tabular}

\begin{tabular}{|l|c|}
\hline CENTRE & QUANTITAT \\
\hline IES Francesc Tàrrega & 4 \\
\hline IES Vila-Roja & 4 \\
\hline Col·legi Torrenova & 3 \\
\hline Col·legi San Cristóbal II & 3 \\
\hline IES Violant de Casalduch & 2 \\
\hline Centre Izquierdo & 1 \\
\hline IES Álvaro Falomir & 1 \\
\hline IES Benigasló & 1 \\
\hline IES Joan Baptista Porcar & 1 \\
\hline IES Alfons XIII & 1 \\
\hline Col·legi Sagrat Cor Mislata & 1 \\
\hline CEED València & 1 \\
\hline
\end{tabular}

Per localitats, en són 984 de Borriana, 45 de Castelló, 23 de Vila-real, 8 de Betxí, 6 de Nules, 6 d'Almassora, 1 de la Vall d'Alba, 1 de la Vall d'Uixó, 1 de Benicàssim i 2 de la província de València. A aquests números cal afegir els 92 que fan preinscripció però directament a la Universitat Jaume I de Castelló per a millorar la seua nota de les PAU, i també els 147 que no fan aquestes proves d'accés perquè procedeixen d'estudis de cicles 
formatius. En aquestes dades hi ha prou estudiantat que consta més d'una vegada perquè han estudiat batxillerat en més d'un centre educatiu.

Per titulacions, les preferències manifestades pels 1.202 estudiantes i estudiants són:

\begin{tabular}{|c|c|}
\hline Grau en Infermeria & 85 \\
\hline Grau en Mestre o Mestra d'Educació Primària & 84 \\
\hline Grau en Mestre o Mestra d'Educació Infantil & 80 \\
\hline Grau en Dret & 62 \\
\hline Grau en Medicina & 59 \\
\hline Grau en Psicologia & 50 \\
\hline Grau en Enginyeria Informàtica & 36 \\
\hline Grau en Administració d’Empreses & 35 \\
\hline Grau en Publicitat i Relacions Públiques & 35 \\
\hline Grau en Ciències de l'Activitat Física i l'Esport & 32 \\
\hline Grau en Traducció i Interpretació & 30 \\
\hline Grau en Periodisme & 29 \\
\hline Grau en Comunicació Audiovisual & 26 \\
\hline Grau en Economia & 24 \\
\hline Grau en Enginyeria en Tecnologies Industrials & 24 \\
\hline Grau en Fisioteràpia & 24 \\
\hline Grau en Biologia & 21 \\
\hline Grau en Estudis Anglesos & 21 \\
\hline Grau en Criminologia i Seguretat & 20 \\
\hline Grau en Finances i comptabilitat & 18 \\
\hline Grau en Enginyeria en Disseny Industrial i Desenvolupament de Productes & 17 \\
\hline Grau en Enginyeria Mecànica & 17 \\
\hline Grau en Relacions Laborals i Recursos Humans & 17 \\
\hline Grau en Fonaments de l'Arquitectura & 15 \\
\hline Grau en Treball Social & 15 \\
\hline Doble Grau en Administració i Direcció d'Empreses i Dret & 14 \\
\hline Grau en Matemàtiques & 14 \\
\hline Grau en Negocis Internacionals (International Business) & 14 \\
\hline Grau en Enginyeria Aeroespacial & 13 \\
\hline Grau en Química & 13 \\
\hline Grau en Administració i Direcció d'Empreses & 12 \\
\hline Grau en Educació Social & 12 \\
\hline Grau en Belles Arts & 11 \\
\hline Grau en Bioquímica i Ciències Biomèdiques & 11 \\
\hline Grau en Turisme & 11 \\
\hline Grau en Disseny i Desenvolupament de Videojocs & 10 \\
\hline Grau en Farmàcia & 9 \\
\hline Grau en Gestió i Administració Pública & 9 \\
\hline Grau en Matemàtica Computacional & 9 \\
\hline Grau en Disseny i Tecnologies Creatives & 8 \\
\hline Grau en Enginyeria Agroalimentària i del Medi Rural & 8 \\
\hline Grau en Enginyeria Elèctrica & 8 \\
\hline
\end{tabular}




\begin{tabular}{|c|c|}
\hline Grau en Biotecnologia & 7 \\
\hline Grau en Ciències Ambientals & 7 \\
\hline Grau en Història i Patrimoni & 7 \\
\hline Grau en Enginyeria Biomèdica & 6 \\
\hline Grau en Estudis Hispànics: Llengua Espanyola i les seues Literatures & 6 \\
\hline Grau en Física & 6 \\
\hline Grau en Odontologia & 6 \\
\hline Grau en Pedagogia & 6 \\
\hline Grau en Administració i Direcció d'Empreses + Dret & 5 \\
\hline Grau en Enginyeria Química & 5 \\
\hline Grau en Farmàcia / Nutrició Humana i Dietètica & 5 \\
\hline Grau en Història & 5 \\
\hline Grau en Enginyeria Civil & 4 \\
\hline Grau en Història de l'Art & 4 \\
\hline Grau en ADE i Turisme & 3 \\
\hline Grau en Ciència i Tecnologia dels Aliments & 3 \\
\hline Grau en Dret + Ciències Polítiques i de l’Administració Pública & 3 \\
\hline Grau en Dret + Criminologia & 3 \\
\hline Grau en Nutrició Humana i Dietètica & 3 \\
\hline Doble Grau en Dret i Criminologia & 2 \\
\hline Doble Grau en Sociologia i Ciències Polítiques i de l’Administració Pública & 2 \\
\hline Grau en ADE i Enginyeria Informàtica & 2 \\
\hline Grau en Arquitectura Tècnica & 2 \\
\hline Grau en Ciències del Mar & 2 \\
\hline Grau en Ciències Polítiques i de l’Administració Pública & 2 \\
\hline Grau en Criminologia & 2 \\
\hline Grau en Enginyeria de l'Energia & 2 \\
\hline Grau en Enginyeria Electrònica Industrial i Automàtica & 2 \\
\hline Grau en Enginyeria en Geomàtica i Topografia & 2 \\
\hline Grau en Enginyeria Multimèdia & 2 \\
\hline Grau en Filosofia & 2 \\
\hline Grau en Gestió Comercial i Màrqueting & 2 \\
\hline Grau en Llengües Modernes i les seues Literatures & 2 \\
\hline Grau en Òptica i Optometria & 2 \\
\hline Grau en Sociologia & 2 \\
\hline Doble Grau en Administració i Direcció d'Empreses i Enginyeria Informàtica & 1 \\
\hline Doble Grau en Dret i Ciències Polítiques i de l’Administració Pública & 1 \\
\hline Doble Grau en Comunicació Audiovisual i Enginyeria de Sistemes de Telecomunicació, So i Imatge & 1 \\
\hline Grau Digital i Multimèdia & 1 \\
\hline Grau en Ciència de Dades & 1 \\
\hline Grau en Comunicació i Relacions Públiques & 1 \\
\hline Grau en Conservació i Restauració de Béns Culturals & 1 \\
\hline Grau en Enginyeria d’Organització Industrial & 1 \\
\hline Grau en Enginyeria i Gestió Empresarial & 1 \\
\hline Grau en Filologia Catalana & 1 \\
\hline Grau en Filologia Clàssica & 1 \\
\hline
\end{tabular}




\begin{tabular}{|l|c|}
\hline Grau en Geografia i Medi Ambient & 1 \\
\hline Grau en Geologia & 1 \\
\hline Grau en Podologia & 1 \\
\hline
\end{tabular}

La informació no apareix separada per universitats sinó per titulacions amb nom coincident. Però una cosa és la preferència de l'estudiantat i una altra ben diferent, que en casos està al voltant del $30 \%$ del total de primeres preferències en la preinscripció, és la titulació que la nota d'admissió els permet estudiar. Cal dir, finalment, que hi ha part d'estudiantat que també demana preinscripció en altres comunitats autònomes, però el total d'alumnat que puga demanar en altres llocs i no en alguna titulació del ventall de graus de les universitats valencianes és mínim, i en seran ben pocs més que aquelles i aquells que desitgen estudiar Veterinària.

Passem a la part final de l'estudi, on veurem què estan estudiant realment els i les joves universitaris borrianencs.

\section{En la zona sud del territori}

Tot i que des de fa temps es tendeix a fer possible i afavorir la mobilitat estudiantil, les dades de quantitat de borrianencs i borrianenques que estan estudiant titulacions universitàries en zones allunyades geogràficament de la nostra ciutat ens fan pensar que poc d'alumnat cursa estudis lluny de Borriana. La típica frase «preferisc estudiar a València», que esgrimeixen els estudiants i estudiantes a l'hora d'escollir el lloc on estudiar, pel que representa independitzar-se de la família durant uns anys i també pel fet que estudiar a València ofereix més oportunitats de relacionar-se socialment i també d'oci i, sobretot, de festa, és una especial motivació que ja no es dona respecte a Alacant, i els nostres compatriotes locals no pensen en l'opció d'estudiar a la Universitat d'Alacant o a la Universitat Miguel Hernández d'Elx, llevat que siga per motius d'habitatge o de manca de nota d'admissió que permeta accedir a estudis físicament més pròxims. També sol ser aquest el motiu pel qual determinat estudiantat cursa estudis universitaris a Terol, Múrcia, Reus... per no poder accedir ací, per insuficient nota d'admissió, al grau universitari desitjat.

Sols 12 estudiants de Borriana estan matriculats actualment en les dues universitats alacantines, 8 a la Universitat d'Alacant (UA) i 4 a la Universitat Miguel Hernández d'Elx (UMH), i d'aquests, 8 són dones (5 i 3, respectivament). A més, hi ha un estudiant que està cursant un màster, en Desenvolupament Local i Innovació Territorial, en la UA.

Pel que fa als graus universitaris, en la UMH hi ha sols un estudiant o estudianta en cada titulació, un en Belles Arts, un en Periodisme, un en Ciències Ambientals i un en Medicina, curiosa aquesta última quantitat, per la gran demanda que té aquesta titulació, i en la UA, n'hi ha un en Publicitat i Relacions Públiques, un en Biologia, un en Turisme i un en Ciències de l'Activitat Física i de l'Esport, a banda dels dos en Geologia i un en Ciències del Mar, aquestes dues últimes titulacions amb la particularitat que no estan en el catàleg de titulacions de la resta d'universitats públiques valencianes, fet que ens fa pensar que el motiu d'aquests tres estudiants d'estar estudiant a Alacant no és per falta de nota d'admissió sinó per una motivació purament vocacional. 


\section{Estudiar a la capital, amb major ventall de ferramentes d'estudi, i també d'oci}

Tal com hem comentat, hi ha joves borrianencs que, encara que puguen estudiar un grau universitari a Castelló, prefereixen anar-se'n a València pel que representa la llibertat de no estar en casa, però també hi ha que estudien allí pel fet que hi ha titulacions que no s'imparteixen a Castelló. De les dues universitats de la ciutat de València, a la Universitat Politècnica de València, la d'estudis més tècnics, n'hi ha 8 que estudien un màster, i 47 que estudien un grau. D’aquests 47, 17 són dones i 30 són homes.

\begin{tabular}{|c|c|c|c|}
\hline GRAU & DONES & HOMES & TOTAL \\
\hline Doble Grau Enginyeria Informàtica -Administració i Direcció d'Empreses & 0 & 2 & 2 \\
\hline Administració i Direcció d’Empreses & 0 & 1 & 1 \\
\hline Arquitectura Tècnica & 0 & 1 & 1 \\
\hline Belles Arts & 2 & 4 & 6 \\
\hline Ciència i Tecnologia dels Aliments & 1 & 0 & 1 \\
\hline Ciències Ambientals & 3 & 1 & 4 \\
\hline Disseny i Tecnologies Creatives & 1 & 1 & 2 \\
\hline Fonaments de l'Arquitectura & 4 & 2 & 6 \\
\hline Enginyeria Aeroespacial & 0 & 2 & 2 \\
\hline Enginyeria Biomèdica & 1 & 1 & 2 \\
\hline Enginyeria Civil & 0 & 1 & 1 \\
\hline Enginyeria de l'Energia & 1 & 1 & 2 \\
\hline Enginyeria d'Obres Públiques & 0 & 1 & 1 \\
\hline Enginyeria d'Organització Industrial & 0 & 1 & 1 \\
\hline Enginyeria Elèctrica & 0 & 1 & 1 \\
\hline Enginyeria Electrònica Industrial i Automàtica & 0 & 1 & 1 \\
\hline Enginyeria en Disseny Industrial i Desenvolupament de Productes & 1 & 0 & 1 \\
\hline Enginyeria en Tecnologies Industrials & 0 & 3 & 3 \\
\hline Enginyeria Forestal i del Medi Natural & 2 & 0 & 2 \\
\hline Enginyeria Geomàtica i Topografia & 0 & 2 & 2 \\
\hline Enginyeria Informàtica & 1 & 1 & 2 \\
\hline Enginyeria Mecànica & 0 & 1 & 1 \\
\hline Enginyeria Química & 0 & 1 & 1 \\
\hline Tecnologia Digital i Multimèdia & 0 & 1 & 1 \\
\hline
\end{tabular}

A la Universitat de València-Estudi General, la primera universitat valenciana, en història i quantitat d'alumnat, hi ha matriculats un total 17 estudiants en màsters i 135 en graus, 57 dones i 78 homes:

\begin{tabular}{|c|c|c|c|}
\hline GRAU & DONES & HOMES & TOTAL \\
\hline Doble Grau Administració d'Empreses - Dret & 1 & 0 & 1 \\
\hline Doble Grau Dret - Ciències Polítiques i de l’Administració Pública & 1 & 0 & 1 \\
\hline Doble Grau Dret - Criminologia & 0 & 2 & 2 \\
\hline Doble Grau Farmàcia - Nutrició Humana i Dietètica & 1 & 1 & 2 \\
\hline
\end{tabular}




\begin{tabular}{|c|c|c|c|}
\hline Doble Grau Sociologia - Ciències Polítiques i de l’Administració Pública & 0 & 1 & 1 \\
\hline Administració i Direcció d’Empreses & 1 & 2 & 3 \\
\hline Biologia & 1 & 3 & 4 \\
\hline Bioquímica i Ciències Biomèdiques & 2 & & 2 \\
\hline Biotecnologia & 1 & 4 & 5 \\
\hline Ciències Ambientals & 3 & 1 & 4 \\
\hline Ciències de l'Activitat Física i de l'Esport & 6 & 2 & 8 \\
\hline Ciències Polítiques i de l'Administració Pública & 3 & . & 3 \\
\hline Comunicació Audiovisual & 1 & & 1 \\
\hline Dret & 3 & 3 & 6 \\
\hline Economia & 2 & 2 & 4 \\
\hline Educació Social & & 2 & 2 \\
\hline Enginyeria Telemàtica & 1 & 2 & 3 \\
\hline Estudis Hispànics & 1 & 1 & 2 \\
\hline Estudis Anglesos & 1 & 3 & 4 \\
\hline Farmàcia & 3 & 5 & 8 \\
\hline Filologia Clàssica & & 1 & 1 \\
\hline Filosofia & 1 & 2 & 3 \\
\hline Física & 3 & 2 & 5 \\
\hline Fisioteràpia & 3 & 3 & 6 \\
\hline Història & 4 & 2 & 6 \\
\hline Història de l'Art & & 1 & 1 \\
\hline Infermeria & 1 & 7 & 8 \\
\hline Llengües Modernes i les seues Literatures & & 1 & 1 \\
\hline Matemàtiques & 3 & 5 & 8 \\
\hline Medicina & 3 & 1 & 4 \\
\hline Negocis Internacionals / International Business & 3 & 2 & 5 \\
\hline Nutrició Humana i Dietètica & 1 & 1 & 2 \\
\hline Odontologia & 1 & & 1 \\
\hline Òptica i Optometria & & 2 & 2 \\
\hline Pedagogia & & 5 & 5 \\
\hline Periodisme & 1 & & 1 \\
\hline Psicologia & & 1 & 1 \\
\hline Química & & 1 & 1 \\
\hline Relacions Laborals i Recursos Humans & & 1 & 1 \\
\hline Treball Social & 1 & 6 & 7 \\
\hline
\end{tabular}

\section{Estar més a prop de casa}

És la Universitat Jaume I, sens dubte per la seua proximitat amb la nostra ciutat, la institució d'estudis superiors que més estudiantat borrianenc té en les seues aules. En tots els seus graus, que ara en són 31 i un doble grau, hi ha matriculat alumnat de Borriana. A més a més, hi ha un total de 40 estudiants i estudiantes cursant algun màster.

Hi ha un total de 463 estudiantes i estudiants matriculats en graus de la Universitat Jaume I, i aquesta és la informació concreta d'estudiantat en aquests graus, separats per branques de coneixement: 


\begin{tabular}{|c|c|c|c|c|}
\hline GRAU & BRANCA DE CONEIXEMENT & DONES & HOMES & TOTAL \\
\hline Química & Ciències & 6 & 3 & 9 \\
\hline Infermeria & Ciències de la Salut & 18 & 4 & 22 \\
\hline Medicina & Ciències de la Salut & 3 & 0 & 3 \\
\hline Psicologia & Ciències de la Salut & 14 & 5 & 19 \\
\hline Arquitectura Tècnica & Enginyeria i Arquitectura & 1 & 2 & 3 \\
\hline Disseny i Desenvolupament de Videojocs & Enginyeria i Arquitectura & 2 & 6 & 8 \\
\hline Agroalimentària i del Medi Rural & Enginyeria i Arquitectura & 2 & 9 & 11 \\
\hline Disseny Industrial i Desenvolupament de Productes & Enginyeria i Arquitectura & 6 & 7 & 13 \\
\hline Enginyeria Elèctrica & Enginyeria i Arquitectura & 2 & 6 & 8 \\
\hline Enginyeria en Tecnologies Industrials & Enginyeria i Arquitectura & 2 & 14 & 16 \\
\hline Enginyeria Informàtica & Enginyeria i Arquitectura & 3 & 13 & 16 \\
\hline Enginyeria Mecànica & Enginyeria i Arquitectura & 1 & 20 & 21 \\
\hline Enginyeria Química & Enginyeria i Arquitectura & 3 & 4 & 7 \\
\hline Matemàtica Computacional & Enginyeria i Arquitectura & 1 & 3 & 4 \\
\hline Estudis Anglesos & Arts i Humanitats & 15 & 6 & 21 \\
\hline Història i Patrimoni & Arts i Humanitats & 2 & 3 & 5 \\
\hline Humanitats i Estudis Interculturals & Arts i Humanitats & 2 & 0 & 2 \\
\hline Traducció i Interpretació & Arts i Humanitats & 15 & 4 & 19 \\
\hline Administració d'Empreses & Ciències Socials i Jurídiques & 7 & 17 & 24 \\
\hline Dret & Ciències Socials i Jurídiques & 29 & 7 & 36 \\
\hline Doble Grau Administració d'Empreses - Dret & Ciències Socials i Jurídiques & 4 & 2 & 6 \\
\hline Comunicació Audiovisual & Ciències Socials i Jurídiques & 2 & 7 & 9 \\
\hline Criminologia i Seguretat & Ciències Socials i Jurídiques & 7 & 3 & 10 \\
\hline Economia & Ciències Socials i Jurídiques & 5 & 12 & 17 \\
\hline Finances i Comptabilitat & Ciències Socials i Jurídiques & 12 & 10 & 22 \\
\hline Gestió i Administració Pública & Ciències Socials i Jurídiques & 9 & 8 & 17 \\
\hline Mestre o Mestra d'Educació Infantil & Ciències Socials i Jurídiques & 25 & 2 & 27 \\
\hline Mestre o Mestra d'Educació Primària & Ciències Socials i Jurídiques & 26 & 17 & 43 \\
\hline Periodisme & Ciències Socials i Jurídiques & 9 & 3 & 12 \\
\hline Publicitat i Relacions Públiques & Ciències Socials i Jurídiques & 8 & 3 & 11 \\
\hline Relacions Laborals i Recursos Humans & Ciències Socials i Jurídiques & 10 & 4 & 14 \\
\hline Turisme & Ciències Socials i Jurídiques & 6 & 2 & 8 \\
\hline \multicolumn{2}{|l|}{ Totals } & 257 & 206 & 463 \\
\hline
\end{tabular}

\section{L'alternativa als estudis públics de tipus presencial. Els borrianencs i borrianenques en la Universitat d'Educació a Distància (UNED)}

Els estudis universitaris públics de les cinc universitats del País Valencià queden complementats pels oferts en la Universitat Nacional d'Educació a Distància (UNED), que té diferents seus en el territori valencià i es caracteritza per uns estudis de caràcter semipresencial o virtual, amb possibilitat de resoldre dubtes per correu electrònic $o$ videoconferència. Aquesta metodologia d'estudi permet cursar un grau universitari a les persones que treballen o que per diferents circumstàncies no poden acudir a classe amb normalitat. És per aquests motius que la UNED és la universitat pública que més 
estudiantat té de totes les de l'Estat espanyol i imparteix, en el present curs 2019-2020, un total de 28 graus.

De les diferents seus de la UNED en les comarques valencianes, 14 en total repartides en 6 a València, 5 a Alacant i 3 a Castelló, sols en dues d'elles hi ha estudiantat borrianenc, en la seu de València i en la de Vila-real. A València hi ha 6 estudiants, 1 cursa el grau en Ciència Política i de l'Administració, de la branca de Ciències Socials i Jurídiques, 3 estudien el grau en Ciències Ambientals, de la branca de Ciències, i 2 el grau en Estudis Anglesos: Llengua, Literatura i Cultura, en la branca d'Arts i Humanitats.

El centre de la UNED a Vila-Real és, per la seua proximitat, el que té la majoria de l'alumnat de la nostra ciutat que cursa estudis en aquesta universitat, amb un total de 72 borrianencs i borrianenques, a més dels 2, ambdós homes, que estan fent estudis de màster, un en el màster en Problemes Socials i un altre en el màster en Ciberseguretat.

Les preferències entre les diferents branques de coneixement de les titulacions universitàries es decanten majoritàriament per les de les titulacions de Ciències Socials i Jurídiques, amb 44 estudiants i estudiantes, dels quals 32 són dones. En Arts i Humanitats n'hi ha total de 14 matriculats (10 homes i 4 dones). Curiosament, en totes les titulacions de la branca de Ciències Socials i Jurídiques hi ha alguns estudiants i estudiantes, però ja no així en les titulacions de Ciències o d'Enginyeria $\mathrm{i}$ Arquitectura, atès que aquests estudis són més difícils d'estudiar de forma virtual. En la branca d'Enginyeria i Arquitectura, tot i que s'ofereixen sis graus, sols en dos d'ells hi ha estudiantat borrianenc, tres en total, tots homes. En Ciències hi ha dos xics en Física i un en Química, però cap estudia Matemàtiques, titulació amb molta demanda actualment i molta antiguitat universitària, ni Ciències Ambientals. En l'única titulació que ofereix la UNED de la branca de Ciències de la Salut, el grau en Psicologia, hi ha 4 homes i 4 dones matriculats.

Les conclusions més evidents que es podrien extraure de les dades estudiades són que l'estudiantat borrianenc que cursa estudis universitaris públics virtuals es decanta pels estudis en ciències socials i humanitats, i que les dones no solen matricular-se en estudis científics d'aquest tipus.

\section{Sobre l'únic grau universitari tradicional que no s’imparteix en el sistema públic}

Actualment, hi ha una gran diversitat de graus universitaris pel fet que són les universitats les que poden dissenyar nous títols segons les seues característiques, professorat i mitjans tècnics. Això ha fet que molts graus s'impartisquen en més d'una universitat, però hi ha una titulació universitària de les més antigues que encara no s'imparteix en el sistema universitari públic valencià.

No podem tindre cap informació sobre una especial titulació universitària amb forta demanda, la de Veterinària, perquè és l'única significativament important que durant anys és sol-licitada socialment per als estudis públics, pel fet que de moment no s'imparteix en cap de les cinc universitats públiques, pel seu elevat cost en infraestructures i convenis privats amb clíniques veterinàries, tot i que està en estudi la seua implantació en la Universitat de València. 


\section{Sobre les universitats privades i la seua nul·la cooperació}

Com a coordinador general de les PAU, durant els anys en què estic exercint el càrrec, ben poques vegades he tingut necessitat de contactar amb les altres universitats de l'àmbit valencià, les privades. Actualment hi ha tres universitats més: són la Universitat Cardenal Herrera-CEU, la Universitat Catòlica San Vicente Mártir, la Universitat Internacional de València (Valencian International University, VIU), i encara una altra més, amb una secció en terres valencianes, la Universidad Europea de Valencia.

Considerava que el treball d'investigació que havia començat a fer sols estaria complet si obtenia la informació de l'estudiantat que estava matriculat en algun dels graus de les universitats privades. Però la meua sorpresa va ser majúscula quan em vaig adonar de les dificultats que em trobava per a l'obtenció d'aquesta informació.

Primerament vaig intentar contactar per telèfon o per correu electrònic. Així com les universitats públiques tenen la seua informació de contacte a l'abast de tots, trobar una forma de contacte directe amb les universitats privades ja era complicat. Pots enviar-los un correu electrònic si ja eres un membre del seu professorat o del seu estudiantat, però si eres algú extern a elles que s'interessa per algun tipus d'informació de la seua estructura universitària, et trobes un mur que no pots saltar. Impossible contactar per telèfon o correu electrònic perquè no hi ha telèfons ni altres mitjans d'informació general.

Rebuscant entre els meus correus per algunes gestions amb personal d'una d'aquestes universitats, sí que vaig poder arribar a comentar telefònicament el que m'interessava saber del seu estudiantat borrianenc, però la resposta de la persona que em contestava des del corresponent servei d'estudiantat, i preferisc no saber qui era, era que aquesta informació que jo sol-licitava (saber quant d'estudiantat borrianenc tenien matriculat en algun dels seus graus universitaris) era confidencial i, per la llei de protecció de dades, no podien donar-me-la. Ni una mínima consulta amb un càrrec superior, resposta negativa immediata i assumpte tancat.

Conclusió: ni el màxim representant de l'accés i l'admissió a la universitat del sistema universitari valencià pot assabentar-se d'una informació tan concreta i intranscendent, des del punt de vista personal, com és saber unes dades numèriques.

Posteriorment, i per a intentar aconseguir per un altre procediment la informació que m'interessava, vaig enviar una carta, en sobre oficial de la meua universitat i firmant-la fent constar el meu càrrec institucional, a cadascuna de les quatre universitats. Resposta? Cap, de cap d'elles. Aquesta falta de collaboració tan notòria fa pensar respecte a la seua transparència en els assumptes de l'admissió en les seues titulacions.

\section{Consideracions finals}

Amb tantes dades sobre preferències i matrícula en la universitat de l'estudiantat borrianenc, és complicat traure unes conclusions que engloben tota la informació estudiada, però sí que podríem dir que hi ha dades molt curioses, com pot ser que ningú estudia per a mestre o mestra fora de Castelló, que les titulacions de l'àmbit de l'arquitectura continuen amb baixa demanda, que la mobilitat de l'estudiantat és mínima, o que en les titulacions amb poca demanda, sol aconseguir-se poder cursar la titulació desitjada però en graus amb 
molta demanda, el percentatge d'alumnat de la nostra ciutat que aconsegueix estudiar el que vol és molt baix. Ara podríem estudiar també fins a quin punt la titulació universitària estudiada influeix o determina el futur treball dels joves borrianencs i borrianenques, però això és, sens dubte, molt més complex d'investigar i constituiria un altre interessant estudi.

\section{BIBLIOGRAFIA}

Per a realitzar aquest article d'investigació, pel tipus d'informació que conté, no s'ha consultat cap llibre o publicació en paper, ni tampoc bibliografia en web. S'ha sol-licitat informació als serveis d'estudiantat de les cinc universitats públiques valencianes i també a les seus de la UNED en el territori valencià. Així mateix, s'ha consultat la base de dades de la preinscripció universitària dels cinc últims cursos acadèmics, informació que té la Conselleria d'Innovació, Universitats, Ciència i Societat Digital de la Generalitat Valenciana.

\section{BIONOTA}

Antoni Gil Trilles (Borriana, 7 de gener de 1962) és llicenciat en Ciències Matemàtiques per la Universitat de València, en 1985, i doctor en Àlgebra per aquesta mateixa universitat, des de 1992. És professor titular d'Universitat de l'àrea de coneixement d'Àlgebra del Departament de Matemàtiques de la Universitat Jaume I. Actualment, des de fa 19 cursos acadèmics, és el coordinador general de les Proves d'Accés a la Universitat (PAU) del sistema universitari valencià.

agil@uji.es 